\title{
Stroke Rehabilitation in Nigeria: Challenges and Opportunities
}

\author{
Auwal Abdullahi
}

\begin{abstract}
Stroke rehabilitation offers opportunity for people with impairments and disabilities secondary to stroke. In this regard, there are many advances particularly in the developed countries. Whereas, in the developing countries such as Nigeria there are still many challenges such as lack of guidelines to guide clinicians and other stakeholders, dearth of the neurological rehabilitation professionals, inadequate training of the existing rehabilitation professionals, poor infrastructure, and lack of policies for stroke rehabilitation. However, there are also opportunities as well such as increased national and global focus on non-communicable diseases, partnership with stakeholders in national and global health, leveraging on democratic governance, leveraging on Sustainable Development Goals (SDGs), and leveraging on the systems through which communities deal with stroke. When these opportunities are harnessed, they can help to improve stroke rehabilitation in the country. Additionally, tackling the challenges headlong can help to improve stroke rehabilitation in Nigeria.
\end{abstract}

Submitted:

Accepted:

Published online:
03 June 2021

02 September 2021 10 September 2021

\section{About the AUTHOR}

Department of Physiotherapy, Bayero University Kano, Nigeria

Contact: Auwal Abdullahi aabdullahi.pth@buk.edu.ng

\section{Introduction}

Stroke is a neurological condition characterized by focal or global neurological deficits of vascular origin that lasts for more than 24 hours or even leads to death in some cases (1). It is a very prevalent condition worldwide as millions of people suffer from it annually according to statistics (2-4), and can pose burdens on the patients, families, health care professionals, and governments both psychosocially and economically (5). Although, most of the statistics of stroke prevalence are from highincome countries, even in the lowincome countries such as the ones in Africa including Nigeria where there seems to be no reliable information on stroke epidemiology, it was suggested that stroke imposes a high burden and is on the rise $(6 ; 7)$. This rise in the incidence and prevalence of stroke in the low-income countries such as Nigeria may hamper the response to stroke cases including rehabilitation (7). The pooled crude incidence and prevalence of stroke in Nigeria were 26.0 [12.839.0] $/ 100,000$ person-years and 6.7 [5.8-7.7] /1000 population respectively, with the incidence and prevalence higher among men than women (7).

Although, there is rise in cases of stroke especially in the developing countries as noted above, one of the interesting epidemiological features of stroke in the recent years is that advancement in its prevention and treatments have curtailed the prevalence of death (8). However, this advancement came with a price tag, as the condition is now one of the leading causes of long-term disability due to the increase in number of those who survive a stroke. For those who survive a stroke, one of the challenges they may face is long-term disability either in motor, perceptual/ sensory, cognitive functions or all (911). Disability following stroke may require rehabilitation for a long time provided usually by a team of experts such as the Clinical Neuropsychologists, 


\section{Research and Best Practice}

Neurologists, Neuro-Occupational therapists, Neurophysiotherapists, Physical Medicine and Rehabilitation Physicians, Rehabilitation Nurses, and Speech therapists among others.

Stroke rehabilitation can be provided during admission, as outpatients or at home. In Nigeria, patients with stroke receive rehabilitation services in the hospital wards (inpatient), as outpatients and at home $(12 ; 13)$. These rehabilitation services take on the medical approach and the patients are usually discharge home to their families upon getting better because of limited rehabilitation resources, the same way it is in countries like South Africa (14). However, in the case of Nigeria, a hospitalbased study reported that, patients prefer outpatient rehabilitation followed by home-based rehabilitation, with the older patients preferring home-based rehabilitation (15). Consequently, in the country, rehabilitation using physiotherapy in patients with acute stroke evaluated with Stroke Rehabilitation Assessment of Movement (STREAM) was shown to improve upper and lower limbs recovery post-intervention (16). Similarly, rehabilitation techniques such as the constraint induced movement (CIMT), neurodevelopmental therapy (NDT), transcranial direct cortical stimulation (tCDs) and task oriented training have been used to improve sensorimotor and cognitive outcomes in patients with stroke in the country (17-20).

The above-mentioned rehabilitation services are provided mainly by the physiotherapists. To achieve the desired and effective rehabilitation outcomes, stroke rehabilitation requires a dedicated and coordinated team effort by the patient, their families and the healthcare providers such as the nurse, the physician, the occupational therapist, the physiotherapist and the speech therapist (21). However, stroke rehabilitation which is supposed to be collaborative and coordinated by the various professionals involved remains uncoordinated and is being carried out in the general medical wards (22). Additionally, in Africa in general including Nigeria, research, development and implementation of rehabilitation guidelines are lacking (23). Furthermore, there are other institutional problems such as inadequate human, material and financial resources, and poorly developed infrastructures such as health facilities, telecommunication and transport systems (24). Even with the reports of burden of stroke in Africa which Nigeria accounts for roughly one fifth of its population, and which is undergoing epidemiological transition like the rest of the world, stroke rehabilitation seems to have a major unused potential despite the challenges. Therefore, the aim of this review is to look at the challenges and opportunities for stroke rehabilitation in Nigeria. For this pur- pose, the search engine PubMed which indexes articles from MEDLINE ${ }^{\circledR}$ and $\mathrm{NLM}^{\circledR}$ was searched using the search strategies, stroke AND rehabilitation AND Nigeria; stroke AND rehabilitation AND Africa from its inception to $24^{\text {th }}$ August, 2021. The two search strategies provided 132 and 280 hits respectively. Relevant literature from the hits was used in writing this review. These opportunities and challenges are depicted in figure 1.

\section{Challenges}

These challenges include, lack of reliable epidemiological information on stroke, lack of guidelines to guide clinicians and other stakeholders, low number of neurological rehabilitation professionals and inadequate teaching and training of the existing rehabilitation professionals $(25 ; 26)$. The other challenges include poor infrastructure, lack of policies for stroke rehabilitation (23;27-29), and poor implementation of policies.

\section{Lack of reliable epidemiological information on stroke}

Reliable epidemiological information on stroke is required for adequate response to its incidence or prevalence. However, this information is lacking in Nigeria, hence hampering response to stroke cases. The only information seems to be available is only on those who attend hospitals which may only comprise of a small percentage of people who suffer from stroke in the country $(6 ; 7)$. Even for them, it may not be possible to get adequate information due to unavailability of adequate human resource and facilities for healthcare services (30;31).

\section{Lack of guidelines for stroke rehabilitation}

Evidence-based guidelines serve as instructional materials to effectively guide practitioners on patients' care. Although guidelines on stroke management and rehabilitation are available courtesy of inputs from multidisciplinary professionals (32); evidence-based treatments, diagnostics, and stroke units are less commonly available or used in low and middle-income countries including Nigeria (26). This seems to be as a result of resource constraint, though other developing countries such as Cameroun (23) had made a notable effort at producing one and South Africa has produced one since close to two decades ago, and has been updating it ever since $(27 ; 33 ; 34)$. Unfortunately, the implementation of the Cameroun's guideline has not been studied due to lack of resources. However, the effort in Cameroun shows that, it is possible and important to have guidelines even in the resource constrained settings. This is because when there are guidelines, efforts of the members of the rehabilitation team may be coordinated, and outcomes as well be improved. Previously, it was shown that well- 


\section{Research and Best Practice}

Figure 1. Schematic representation of challenges and opportunities for stroke rehabilitation in Nigeria

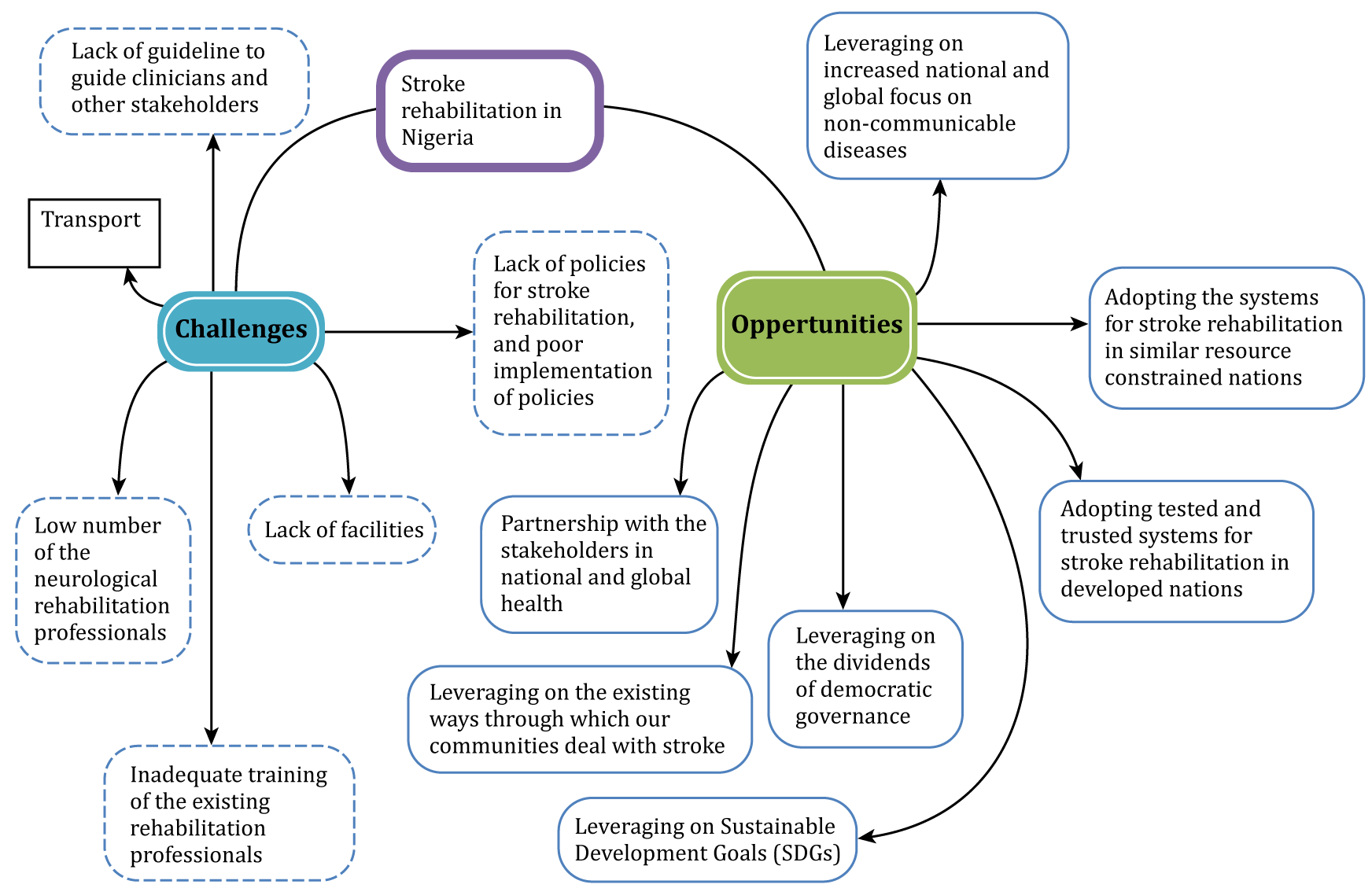

coordinated rehabilitation in a stroke unit had led to better outcomes (35-37). Thus, national guideline for stroke rehabilitation in Nigeria is urgently needed. This is possible since a similar guideline on acute care of neurotrauma has recently been developed (38).

Low number of professionals in neurological rehabilitation

Another challenge is the low number of professionals who should run the affairs of stroke rehabilitation. Even in the presence of adequate number of rehabilitation professionals, for the desired outcomes to be achieved, there needs to be coordination by the team including all the members of the rehabilitation team such as the nurse, the physician, the occupational therapist, the physiotherapist and the speech therapist (21). Notably, there seems to be not many trained Physiotherapists, Rehabilitation Physicians and Nurses and other stakeholders across the nation. For instance, trained Physiotherapists in Neurological Rehabilitation are less than 100 as of 2016 (25). Therefore, there is need for the existing professionals to inspire others to follow suit so that Nigeria can have more trained staff in rehabilitation. Another factor that compounds the low number of professionals in Neurological Rehabilitation is the lack of coordination among them. According to Bell-Gam et al., stroke rehabilitation which is supposed to be collaborative and coordinated by the various professionals involved remains uncoordinated and is being carried out in the general medical wards (22).

Inadequate training of the existing rehabilitation professionals

There may be many Occupational therapists, Neurologists and Physiotherapists in some countries in Africa including Nigeria. However, how many of them are trained in the arts of neurological rehabilitation especially in the state of the art stroke rehabilitation? The answer may be a resounding, few! A recent study (39) in a Nigerian population has shown that Physiotherapists lean largely on personal choices rather than evidencebased practice for stroke rehabilitation. Similarly, Owolabi (31) asserted that, there is lack of trained rehabilitation clinicians in Africa in general. In addition, lack of research skills and the ability to appraise the literature have also been noted (40). However, the situa- 
tion is different in some parts of the world. For instance, in the UK (41) and South Africa $(27 ; 34)$, there are Stroke Specialists who specialized in the discipline of stroke rehabilitation. Additionally, in Austria there is a special master's degree in stroke medicine (42). Thus, training is important for acquiring knowledge and skills. Consequently, task shifting training from the Neurologists was reported to improve stroke knowledge among Nurses in a Nigerian population (43). Furthermore, the training should include critical thinking, information retrieval and literature synthesis for clinical decision making.

\section{Lack of policies for stroke rehabilitation}

Policies are programs adopted by a government or a system. Unfortunately, the health policies in the low resource countries do not include rehabilitation since it is not yet considered a priority in such countries $(28 ; 44)$. Similarly, in Nigeria, there is not any policy for stroke rehabilitation. Additionally, there is always poor implementation of policies in developing countries $(45 ; 46)$. Lack of policies for stroke rehabilitation, and poor implementation of policies can jeopardize stroke rehabilitation in Nigeria and leave the patients to live with disability in the long-term. Consequently, the government needs to decisively face stroke burden by setting policies that advance improved care of patients with stroke (47).

Out of pocket payment by the patients or their families

There are many barriers to access to rehabilitation services which include cost of medication, payment for services and transportation constraints $(48 ; 49)$. Such costs are borne by the patients or their families (15). However, this is not an easy responsibility considering the rising inflation faced by the citizenry partly due to unfavourable economic policies and the Covid-19 pandemic. Therefore, the government needs to take urgent steps to subsidize healthcare in general for her citizenry.

\section{Lack of facilities}

In Africa in general including Nigeria, facilities and human resources for prevention, investigations, acute care and rehabilitation of patients with stroke are lacking (31). Consequently, this can lead to limited access to rehabilitation and health services (50). In particular, during the period of lockdown due to Covid-19, many patients including those with stroke were left out of service. This was because there was no arrangement to provide care for patients during the period.

\section{Transport}

Ease of transportation is important for getting to the clinic and meeting appointments. However, for patients with stroke in developing countries including Nigeria, transport is a major constraint $(48 ; 49)$. In particular during the lockdown due to Covid-19, everything including transport was completely shutdown.

\section{Opportunities}

Although there are so many challenges for stroke rehabilitation in Nigeria, opportunities still also abound. The opportunities include leveraging on increased global and national focus on non-communicable diseases, partnership with stakeholders in national and global health, leveraging on dividends of democratic governance, and leveraging on sustainable development goals (SDGs). Other opportunities include leveraging on the existing ways through which our communities deal with stroke, adopting systems for stroke rehabilitation in similar resource constraint nations and adopting tested and trusted systems for stroke rehabilitation in developed nations.

Leveraging on encreased national and global focus on non-communicable diseases

Nigeria like the rest of the world is also undergoing epidemiological transition. According to Omran (51), epidemiological transition occurs as a result of increased in public and environmental health. Due to epidemiological transition, infectious diseases are being replaced by chronic non-infectious diseases as such stroke, diabetes and cardiovascular diseases (52). Since governments and other stakeholders are aware of the change in terrain of the public health, their efforts in healthcare system may focus on chronic conditions such as stroke. Thus, rehabilitation services which most patients with chronic conditions require can be made readily available.

\section{Partnership with stakeholders in national and global health}

Stroke rehabilitation requires partnership between all stakeholders such as the academia, non-governmental organizations, the industry and the government. When there is a strong partnership among stakeholders, the target goals can be achieved. For instance, formidable partnership between stakeholders such as the World Health Organization and other United Nations agencies has helped in curtailing the incidence of various conditions such as malaria in Africa (53). Similarly in Nigeria, if there will be concerted efforts between the various stakeholders; the rehabilitation professionals and the policy makers, goals for stroke rehabilitation can be achieved.

\section{Leveraging on democratic governance}

According to the United Nations Development Program, many more countries than ever before are working to 
build democratic governance and their challenge is to develop institutions and processes that are more responsive to the needs of ordinary citizens (54). Thus, Democratic governance guarantees human right which includes right for health.

In Nigeria for instance, there are three tiers of her democratic governance. These tiers are the executive, the legislator and the judiciary (55). The legislator enacts laws and passes bills into laws. The executive assents the bills or laws; and the judiciary enforces and ensures compliance with the bills or laws. Thus, pressure groups such as patients' association or professional associations can put forward their interest like setting up stroke units in every secondary and tertiary hospital which can be sponsored as a bill by the legislator; and eventually be passed, and assented into law by the executive. These show that, following the tenets of democratic governance, opportunities are abound to have and implement good policies on rehabilitation by governments at various levels. At the moment pressure groups such as Stroke Association Nigeria founded in 2012 are springing up to help improve stroke prevention, treatment and rehabilitation (56).

\section{Leveraging on Sustainable Development Goals (SDGs)}

Sustainable Development Goals (SDGs) are 17 target goals aimed at ending poverty, protecting the planet and ensuring prosperity for all (57). Each goal has specific targets expected to be achieved by 2030. The third of SDGs is Good Health and Well-being of which rehabilitation is a key part and parcel. Many countries including Nigeria are signatories to SDGs. Thus, this is an opportunity that can leveraged on by Nigeria to improve her health services including stroke rehabilitation for them to achieve the set objectives of the SDGs, provide and improve health for all. However, the inability to achieve the millennium developmental goals by many countries including Nigeria casts doubts on the prospects of her achieving health and well being for all by 2030 . Consequently, keying into the opportunities presented by increasing focus by Nigeria on non-communicable disease as a result of epidemiological transition, opportunity for partnership with multinational organizations such as the WHO and democratic governance can help the country to achieve her desired health goal including that of stroke rehabilitation.

Leveraging on the existing ways through which our communities deal with stroke

Beliefs on the cause of stroke may differ from one community to another. In African-Caribbean communities in the UK, witchcraft is believed to be a cause of stroke (58). Similarly, in Nigeria many people seem to still believe that stroke in caused by spiritual attack or witchcraft. As a result of this, people with stroke may tend to get help from spiritual or religious leaders rather than coming to the hospital. Community based rehabilitation involving the spiritual or the religious leaders can help improve access to rehabilitation in Nigeria. Stroke rehabilitation is better when it is provided at the patients' places of domicile (12). Additionally, the caregivers of stroke survivors in Nigeria are passionate about helping their wards with carrying out tasks or responsibilities. This gesture can be modified to encouraging the wards towards independence in activities of daily living (ADL).

Adopting systems for stroke rehabilitation in similar resource constraint nations

There exist two guidelines for stroke rehabilitation in Africa. These guidelines are in Cameroun and South Africa $(23 ; 27 ; 34)$. However, only that of South Africa the implementation was investigated. In the South African guideline, there are stroke specialists from all disciplines involved in neurological rehabilitation. Additionally, there are equipment and expertise need at the three levels of healthcare (primary, secondary and tertiary). The tertiary level has the near state of the arts equipment in neuroradiology and stroke specialists which are available 24 hourly. Thus, this system which ensures basic treatments at the primary and secondary levels and timely referral to the tertiary level for expert care can be adopted in Nigeria.

Adopting tested and trusted systems for stroke rehabilitation in developed nations

According to Olalaye et al., stroke rehabilitation is best provided in the patients' places of domicile (12). However, stroke rehabilitation is still largely provided in the hospitals in Nigeria. In the UK for instance, according to the National Institute for Health and Care Excellence (59), in patient stroke rehabilitation is provided during the acute stage in the conventional hospital system; and during the post-acute stage, in in-patient specialized rehabilitation clinics and in the community. If this type of system can be adopted, it will bring rehabilitation services at the doorsteps of the patients in Nigeria. This will be better if clinicians are trained to become Stroke Specialists.

\section{Telerehabilitation}

Telerehabilitation is used to substitute for the traditional face-to-face, and it has been reported to improve outcomes in people with stroke (60-62). Covid-19 pandemic has changed the health system landscape of so many countries. This is because of the partial or total lockdown imposed by many countries whereby everyone had to stay at home. However, in Nigeria the health facilities 
totally shut down and stroke survivors were left without any help. Therefore, even with the pandemic, since stroke is a long-term condition and the patient can be taught on how to self-manage themselves $24 / 7$ with success (63); telerehabilitation model can be adopted for patients with stroke in Nigeria. This can be cost-effective since the patients may not have to spend on transport and their care particularly as patients in Nigeria pay out of their pockets for health services (15). Similarly, it can also help save the healthcare provider's time, thereby enabling them to focus on patients who must be seen by them.

Research efforts in stroke care and rehabilitation Over the years, many researchers have made efforts in stroke rehabilitation research in Nigeria. So far, areas these researchers have looked at include issues on caregivers (64), quality of life (65), movement rehabilitation (17-18;66), activities of daily living (67), transcortical direct stimulation (19) and community reintegration (68).

\section{Conclusion}

Although there are many challenges to stroke rehabilitation in Nigeria such as lack of guidelines for stroke rehabilitation and professionals in stroke rehabilitation, there exist corresponding opportunities such as leveraging on the systems through which communities deal with stroke, current research efforts in stroke rehabilitation, telerehabilitation and adopting systems already in place in similar resource constrained countries. When these opportunities are harnessed, they can help in improving stroke rehabilitation in Nigeria. Similarly, tackling the challenges thereof can help in improving stroke rehabilitation in the country. In addition, the strength of this article is that, it can serve as a foundation upon which researchers and clinicians in stroke rehabilitation and other stakeholders can step to help improve stroke rehabilitation in Nigeria. However, the scarcity of literature on the issues raised is a limitation of this paper.

Competing interests: None declared.

Funding: None declared.

Patient content: Not applicable.

Ethics approval: Not applicable.

\section{References}

(1) Hatano S. Experience from a multicentre stroke register: a preliminary report. Bullettin of WHO. 1976; 54:541-53.

(2) World Health Organization (2008). Global Burden of Disease (GBD) 2004 update. Geneva, Switzerland: WHO. Available from http:// www.who.int/healthinfo/global burden disease/2004 report update/en/.

(3) Strong K, Mathers CD, Bonita R. Preventing stroke: saving lives around the world. Lancet Neurol. 2007; 6:182-7. doi:10.1016/S14744422(07)70031-5.
(4) Feigin VL, Forouzanfar $\mathrm{MH}$, Krishnamurthi R, et al. Global Burden of Diseases, Injuries, and Risk Factors Study 2010 (GBD 2010) and the GBD Stroke Experts Group. Global and regional burden of stroke during 1990-2010: findings from the Global Burden of Disease Study 2010. Lancet. 2014; 383:245-54. doi:10.1016/s0140-6736(13)61953-4.

(5) Saka Ö, McGuire A, Wolfe C. Cost of stroke in the United Kingdom. Age and Ageing. 2009; 38:27-32. doi:10.1093/ageing/afn281.

(6) Adeloye D. An Estimate of the Incidence and Prevalence of Stroke in Africa: A Systematic Review and Meta-Analysis. PLOS ONE. 2014; 9. doi:10.1371/journal.pone.0100724.

(7) Adeloye D, Ezejimofor M, Auta A, et al. Estimating morbidity due to stroke in Nigeria: a systematic review and meta-analysis. J Neurol Sci. 2019; 402:136-44. doi:10.1016/j.jns.2019.05.020.

(8) Bejot Y, Benatru I, Rouaud O, et al. Epidemiology of stroke in Europe: geographic and environmental differences. J Neurol Sci. 2007; 262:85-8. doi:10.1016/i.jns.2007.06.025.

(9) Murray CIL, Lopez AD. Global mortality, disability and the contribution of risk factors. Global burden of the disease study. Lancet. 1997; 349:1436-42. doi:10.1016/S0140-6736(96)07495-8.

(10) Boult C, Kane RL, Louis TA, Boult L, McCaffrey D. Chronic conditions that lead to functional limitation in the elderly. J Gerontol Med Sci. 1994; 49:M28-36. doi:10.1093/geronj/49.1.m28.

(11) van den Bos GAM. The burden of chronic diseases in terms of disability, use of health care and healthy life expectancies. Eur J Public Health. 1995; 5:29-34. doi:10.1093/eurpub/5.1.29.

(12) Olaleye OA, Hamzat TK, Owolabi MO. Stroke rehabilitation: should physiotherapy intervention be provided at a primary health care centre or the patients' place of domicile? Disabil Rehabil. 2014; 36:49-54. doi:10.3109/09638288.2013.777804.

(13) Olaleye OA, Lawal ZI. Utilization of physiotherapy in the continuum of stroke care at a tertiary hospital in Ibadan, Nigeria. Afr Health Sci. 2017; 17:79-87. doi:10.4314/ahs.v17i1.11.

(14) Ntsiea MV. Current stroke rehabilitation services and physiotherapy research in South Africa. S Afr J Physiother. 2019; 75:475. doi:10.4102/sajp.v75i1.475.

(15) Vincent-Onabajo G, Mohammed Z. Preferred rehabilitation setting among stroke survivors in Nigeria and associated personal factors. Afr J Disabil. 2018; 7:352. doi:10.4102/ajod.v7i0.352.

(16) Olawale OA, Julius SO. Evaluation of Motor Recovery in Adult Patients with Hemiplegic stroke. Nigerian Quarterly J Hospital Med. 2005; 16:10-3. doi:10.4314/nqjhm.v16i1.12787.

(17) Abdullahi A. Effects of Number of Repetitions and Number of Hours of Shaping Practice during Constraint-Induced Movement Therapy: A Randomized Controlled Trial. Neurol Res Int. 2018; 5496408. doi:10.1155/2018/5496408.

(18) Abba MA, Muhammad AS, Badaru UM, Abdullahi A. Comparative effect of constraint-induced movement therapy and proprioceptive neuromuscular facilitation on upper limb function of chronic stroke survivors. Physiother Quart. 2020; 28:1-5. doi:10.5114/pq.2020.89809.

(19) Hassan AB, Danazumi MS, Yakasai AM, Abdullahi A. Effect of Transcranial Direct Current Stimulation (tDCS) Delivered via Dorsolateral Prefrontal Cortex on Central Post-stroke Pain and Depression: A Case Report. Physiother Theory Pract. 2020. doi:10.1080/09593985.2021.1891591.

(20) Lawal IU, Hillier SL, Hamzat TK, Rhoda A. Effectiveness of a structured circuit class therapy model in stroke rehabilitation: a protocol for a randomized controlled trial. BMC Neurology. 2015; 15:88. doi:10.1186/s12883-015-0348-7.

(21) Winstein CJ, Stein J, Arena R, et al. Guidelines for Adult Stroke Rehabilitation and Recovery: A Guideline for Healthcare Professionals From the American Heart Association/American Stroke Association. Stroke. 2016; 47:e98-169. doi:10.1161/STR.0000000000000098.

(22) Bell - Gam HI, Onwuchekwa A, lyagba AM. Improving Stroke Management through Specialized Stroke Units in Nigeria: A situational Review. Nigerian Health J. 2012; 12: 31-4. 
(23) Cockburn L, Fanfon TN, Bramall A, et al. Best practice guidelines for stroke in Cameroon: An innovative and participatory knowledge translation project. Afr J Disabil. 2014; 3:92. doi:10.4102/ajod.v3i1.92.

(24) Garbusinski JM, van der Sande MA, Bartholome EJ, et al. Stroke presentation and outcome in developing countries: a prospective study in the Gambia. Stroke. 2005; 36:1388-93. doi:10.1161/01.STR. $0000170717.91591 .7 \mathrm{~d}$

(25) Hamzat TK. Some Challenges Facing Neurorehabilitation in Nigeria: Standpoint of a Neurophysiothrapists. J Neurol Neurorehabil Res. 2016; 1:201.

(26) Langhorne $\mathrm{P}, \mathrm{O}$ 'Donnell MJ, Chin SL, et al. Practice patterns and outcomes after stroke across countries at different economic levels (INTERSTROKE): an international observational study. Lancet. 2018; 391:2019-27. doi:10.1016/S0140-6736(18)30802-X.

(27) Bryer A, Connor M, Haug P, et al. South African guideline for management of ischaemic stroke and transient ischaemic attack 2010: a guideline from the South African Stroke Society (SASS) and the SASS Writing Committee. S Afr Med J. 2010; 100:747-78. doi:10.7196/samj.4422.

(28) Khan F, Amatya B, Mannan H, Rathore FA. Neurorehabilitation in Developing Countries: Challenges and the Way Forward. Phys Med Rehabil Int. 2015; 2:1070.

(29) Rhoda A, Cunningham N, Azaria S, Urimubenshi G. Provision of inpatient rehabilitation and challenges experienced with participation post discharge: quantitative and qualitative inquiry of African stroke patients. BMC Health Serv Res. 2015; 15:423. doi:10.1186/ s12913-015-1057-z.

(30) Owolabi M (2015). Neurorehabilitation in Developing Countries Time for Action. Available from wfnr.co.uk/download/MjYo.

(31) Owolabi MO. Taming the burgeoning stroke epidemic in Africa: stroke quadrangle to the rescue. West Indian Med J. 2011;60(4):412-21.

(32) Quinn TJ, Paolucci S, Sunnerhagen KS, et al. Evidence-based stroke rehabilitation: an expanded guidance document from the european stroke organisation (ESO) guidelines for management of ischaemic stroke and transient ischaemic attack 2008. J Rehabil Med. 2009; 41:99-111. doi:10.2340/16501977-0301.

(33) Kenge A, Anderson C. The neglected burden of stroke in Sub-Saharan Africa. Int J Stroke. 2006; 14:180-9. doi:10.1111/i.1747-4949.2006. 00064.x.

(34) Bryer A, Connor MD, Haug P, et al. The South African guideline for the management of ischemic stroke and transient ischemic attack: recommendations for a resource-constrained health care setting. Int J Stroke. 2011; 6:349-54. doi:10.1111/j.1747-4949.2011.00629.x.

(35) Jorgensen HS, Nakayama $\mathrm{H}$, Raaschou HO. The effect of a stroke unit: reductions in mortality, discharge rate to nursing home, length of hospital stay, and cost. Stroke. 1995; 26:1178-82. doi:10.1161/01.str. 26.7.1178.

(36) Indredavik B, Bakke F, Solberg R. Benefit of a stroke unit: a randomised controlled trial. Stroke. 1991;22: 1026-31. doi:10.1161/ 01.str.22.8.1026

(37) Langhorne P, Williams BO, Gilchrist W, Howie K. Do stroke units save lives? Lancet. 1993; 342: 395-8. doi:10.1016/0140-6736(93)92813-9.

(38) Emejulu JK, Malomo A, Oremakinde A, Onyia C, Nwaribe E, Ekweogwu O, Oseni A, Opara O, Iroegbu-Emeruem L, Otorkpa E, Komolafe E, Bankole O, Shehu B. Developing a Guideline for Neurotrauma in Nigeria. World Neurosurg. 2020; 138:e705-11. doi:10.1016/i.wneu.2020.03.036.

(39) Abdullahi A, Abdu YY, Abba MA. What Do Physiotherapists Do in Stroke Rehabilitation: A Focus Group Discussion. Nigerian J Med Rehabil. 2015;18.

(40) Ibikunle PO, Onwuakagba IU, Maduka EU, Okoye EC, Umunna JO. Perceived barriers to evidence-based practice in stroke management among physiotherapists in a developing country. J Eval Clin Pract. 2021; 27:291-306. doi:10.1111/jep.13414.
(41) University Hospital Southampton (2014). Specialists Stroke Nurses: Stroke nurse practitioners. Available from https://www.uhs.nhs.uk/ OurServices/Brainspineandneuromuscular/Strokeservices/Meetthet eam/Specialiststrokenurses.aspx (Accessed on 17/08/2021).

(42) Danube University Krems. European Master in Stroke Medicine. Available from https://www.donau-uni.ac.at/en/university/faculties /health-medicine/departments/clinical-neurosciences-preventivemedicine/teaching/european-master-in-stroke-medicine.html (Accessed on 17/08/2021).

(43) Akinyemi RO, Owolabi MO, Adebayo PB, et al. Task-shifting training improves stroke knowledge among Nigerian non-neurologist health workers. J Neurol Sci. 2015; 359:112-6. doi:10.1016/j.jns.2015.10.019.

(44) Morris LD, Grimmer KA, Twizeyemariya A, Coetzee M, Leibbrandt DC Louw QA. Health system challenges affecting rehabilitation services in South Africa. Disabil Rehabil. 2021;43(6):877-883. doi:10.1080 L09638288.2019.1641851.

(45) Makinde T (2005). Problems of Policy Implementation in Developing Nations: The Nigerian Experience. J Soc Sci. 2005; 11:63-9. doi:10.1080/09718923.2005.11892495.

(46) Imurana BA, Haruna RK, Kofi A-B N. The Politics of Public Policy and Problems of Implementation in Africa: An Appraisal of Ghana's National Health Insurance Scheme in Ga East District. Int J Humanities Soc Sci. 2014; 4:196-207.

(47) Chimatiro GL, Rhoda AJ. Scoping review of acute stroke care management and rehabilitation in low and middle-income countries. BMC Health Serv Res. 2019;19:789. doi:10.1186/s12913-019-4654-4.

(48) Baatiema L, Sanuade O, Kuumuori Ganle J, Sumah A, Baatiema L, Sumankuuro J. An ecological approach to understanding stroke experience and access to rehabilitation services in Ghana: A crosssectional study. Health Soc Care Community. 2021; 29:e67-78. doi:10.1111/hsc.13243.

(49) Onyeso OKK, Umunnah JO, Ezema Cl et al. Profile of practitioners, and factors influencing home care physiotherapy model of practice in Nigeria. Home Health Care Serv Q. 2020;39:168-83. doi:10.1080/ 01621424.2020 .1754315$.

(50) Kalavina R, Chisati E, Mlenzana N, Wazakili M. The challenges and experiences of stroke patients and their spouses in Blantyre, Malawi. Malawi Med J. 2019; 31:112-7. doi:10.4314/mmj.v31i2.2.

(51) Omran AR. The epidemiological transition: A theory of the epidemiology of population change. The Milbank Quarterly. 1971; 83: 731-57.

(52) Gatongi PM, Songa J, Kiyiapi L. The Principles of Epidemiologic Transition And The Experiences In Kenya. Pinnacle Med Medical Sci. 2015; 2:689-92.

(53) Lemogoum D, Degaute, JP, Bovet P. Stroke Prevention, Treatment and Rehabilitation in Sub-Saharan Africa. Am J Preventive Med. 2005; 29:95-101. doi:10.1016/i.amepre.2005.07.025.

(54) Chatham House. The importance of democracy. Available from https://www.chathamhouse.org/2021/04/importance-democracy (Accessed on 07/09/2021)

(55) Nwagwu EJ. Legislative Oversight in Nigeria: a Watchdog or a Hunting Dog? J Law Policy Global. 2014; 22:16-32.

(56) Femisco M. Raising stroke awareness in Nigeria. Available from https://www.changemakers.com/rwjfopen/ideas/entries/raisingstroke-awareness-nigeria (Accessed on 07/09/2021).

(57) United Nations. \#Envision2030: 17 goals to transform the world for persons with disabilities. Available from https://www.un.org/ development/desa/disabilities/envision2030.html (Accessed on 07/09/2021).

(58) Moorley C, Cahill S, Corcoran N. Stroke among African-Caribbean women: lay beliefs of risks and causes. J Clin Nurs. 2016; 25:403-11. doi:10.1111/jocn.13061.

(59) National Institute for Health Care Excellence (NICE, 2013). Stroke rehabilitation in adults: Clinical guideline [CG162]. Available from https://www.nice.org.uk/guidance/cg162 (Accessed on 07/09/2021) 


\section{Research and Best Practice}

(60) Carey JR, Durfee WK, Bhatt E, et al. Comparison of finger tracking versus simple movement training via telerehabilitation to alter hand function and cortical reorganization after stroke. Neurorehabil Neural Repair. 2007; 21:216-32. doi:10.1177/1545968306292381.

(61) Peretti A, Amenta F, Tayebati SK, Nittari G, Mahdi SS. Telerehabilitation: Review of the State-of-the-Art and Areas of Application. JMIR Rehabil Assist Technol. 2017;4:e7. doi:10.2196/ rehab.7511.

(62) Olldashi F, Latifi R, Parsikia A, et al. Telemedicine for Neurotrauma Prevents Unnecessary Transfers: An Update from a Nationwide Program in Albania and Analysis of 590 Patients. World Neurosurg. 2019; 128:e340-6. doi:10.1016/j.wneu.2019.04.150.

(63) Jones F, McKevitt C, Riazi A. How is rehabilitation with and without an integrated self-management approach perceived by UK community-dwelling stroke survivors? A qualitative process evaluation to explore implementation and contextual variations. BMJ Open. 2017; 7:e014109. doi:10.1136/bmjopen-2016-014109.

(64) Badaru UM, Ogwumike OO, Adeniyi AD, Nelson EE. Determinants of caregiving burden and quality of life of informal caregivers of African stroke survivors: literature review. International Journal on Disab Human Dev. 2017; 16:249-58. doi:10.1515/ijdhd-2016-0041.

(65) Ogwumike OO, Omoregie AA, Dada OO, Badaru UM. Quality of life of stroke survivors: A cross-sectional study of association with functional independence, self-reported fatigue and exercise selfefficacy. Chronic IIIn. 2021; 17423953211023960. doi:10.1177/ 17423953211023960.

(66) Abdullahi A, Umar NA, Ushotanefe U, et al. Effects of two different modes of tasks practice during lower limbs constraint-induced movement therapy in people with stroke: a randomized clinical trial. Neural plasticity. 2021; 6664058. doi:10.1155/2021/6664058.

(67) Makama RI, Abdullahi A, Badaru UM, Abba MA, Zakari MK, Bello B (2018). What do caregivers of stroke survivors consider as activities of daily living: a qualitative interview and a descriptive survey? Fizjoterapia - wiedza i doświadczenie

(68) Akosile C, Nworah C, Okoye E, Adegoke B, Umunnah J, Fabunmi A Community reintegration and related factors in a Nigerian stroke sample. Afr Health Sci. 2016; 16:772-80. doi:10.4314/ahs.v16i3.18. 